\title{
GERARDO TORRES
}

\section{Las ruinas que heredamos*}

TY ÖLDERLIN fue, entre las voces de su tiempo, la más pura. H Y también la más honda. Porque la pureza tiene su raíz en el abismo que separa a la vida de la vida. Pero un poeta como él no podía andar impunemente entre los hombres: "Pronto parte aquél por quien habló el espíritu". Sin embargo, poco antes de internarse en ese bosque de sombras luminosas que fue su locura, Hölderlin vio con admirable claridad los aciagos signos de su época - que también es la nuestra-y profetizó el día en que habremos de reconciliarnos con los dioses y con el mundo. Comenzaba el siglo XIX. Jean Paul había anunciado ya la muerte de Dios y Marx no tardaría en condenar al Capitalismo. Nietzsche acabaría por decapitar a la moral y Freud nos haría dudar del origen de nuestros actos al comienzo de un siglo XX que había nacido muerto. Como al principio, la casa del hombre fue otra vez inhabitable y ajena Babel volvió a repetirse, pero esta vez en las ideas. El sentido de la poesía fue olvidado: perdido el nexo que unía al hombre con el cielo y la tierra, todo estaba perdido.

El primer poeta que se dio cuenta de este naufragio universal fue, precisamente, Hölderlin:

¡Pero llegamos demasiado tarde, amigo! Sin duda los dioses aún viven, pero encima de nuestras cabezas, en otro mundo; allá obran sin cesar, sin ocuparse de nuestra suerte, , Tanto nos cuidan los inmortales! Pues a menudo un frágil navío no puede contenerlos, y el hombre de 1985

* Fragmento de la conferencia Poesia vara qué dictada en el ITAM el día 24 de abril 
no soporta más que por instantes la plenitud divina.

Después la vida no es sino soñar con ellos. Pero el yerro es útil, como el sueño, y la angustia y la noche fortalecen mientras llega la hora en que aparezcan muchos héroes crecidos en cuna de bronce, valerosos como dioses. Vendrán como trueno. Entre tanto, a veces se me ocurre que es mejor dormir que vivir sin compañeros y en constante espera. ¿Qué hacer hasta ese día futuro? ¿Qué decir? No lo sé. ¿Para qué poetas en estos tiempos de miseria?

Pero son, me dices, semejantes a los sacerdotes del dios de las viñas, que en las noches sagradas andaban de un lugar a otro.

El comienzo y el final de la estrofa son terribles. Por una parte nos condenan a vivir fuera de tiempo ("Llegamos demasiado tarde, amigo") y, por la otra, este mismo destiempo nos hace herederos del silencio y la inmovilidad ("Entre tanto, a veces se me ocurre que es mejor dormir que vivir sin compañeros y en constante espera. ¿Qué hacer hasta ese día futuro? ¿Qué decir? No lo sé”). Cuando el hombre apareció los dioses ya no estaban. Están en otra parte: el tiempo de los dioses y el tiempo de los hombres es distinto. Distinto, sí, pero no incomunicable. Si los dioses se marcharon, de ellos nos hablan aún las cosas que los vieron. Hay que saber oír: permanecer en silencio, no moverse: contemplar. Sólo así podremos estar a tiempo o dentro del tiempo o de los tiempos.

La contemplación es un estado transitorio. Finalmente, hay que regresar a la vida: comer, dormir, hacer el amor, trabajar..., levantar el puente que nos une instantáneamente con ese más allá de siempre que es nuestro fin y el principio de todo lo humano. A hí también nos esperan el silencio y la inmovilidad, pero encubiertos. Así, el silencio puede aparecer bajo la forma de parlanchinería sin sentido, y la inmovilidad, de continua actividad, monótona y vana. Lo que era axis mundi puede ser también negación del hombre y negación de la vida.

La significación plena - exceso de ser-que se experi-

** Traducción de Federico Gorhea. 
menta en la contemplación, en la vida cotidiana puede llegar a ser insignificante o absurda. Me llama la atención que la palabra absurdo se derive de sordo: lo que no se oye o el que no oye. No oímos o no se oye lo que esta lejos y fuera de nosotros. Paradójicamente estamos dentro y fuera del mundo al mismo tiempo. Quien guarda la llave es el poeta.

Al silencio lo sella la palabra y, a la inmovilidad, el ritmo. Ritmo y palabra: verso: instrumento - llave- que sirve para mostrarnos el dentro y el fuera de esta vieja mansión abandonada por sus antiguos moradores. Ruinas y sombras. Ecos y escombros. Cenizas. No comprendemos. Y lo poco que ha sido revelado por los poetas crea en nosostros fe o angustia. Amamos o criticamos, pero nunca comprendemos. No nos ha sido dado conocer, aunque a veces y sin más la dicha parezca venir del fondo de las cosas y nos purifique y nos reconcilie con el mundo y con nosotros mismos y pur un instante no seamos más extranjeros en nuestra propia tierra.

Han sido los poetas -y no los profetas- quienes han hecho más habitable el paraíso en ruinas que heredamos. Para los profetas la felicidad siempre está en el futuro; para los poetas, en el presente. Estos reviven el origen: el pasado es el presente. Viven en medio del incendio que con su hermosura calcinó a la tierra. Leen en las cenizas y en las pavesas frases de algún dios que se quedaron prendidas en los labios de las piedras. Captan al vuelo la inextricable señal del páiaro y aprenden el misterioso lenguaje de los árboles. Conversan con los animales y discuten con las flores. Descubren en el fango las migajas de un banquete al que aun no hemos sido invitados.

Pero no dijo Hölderlin que es "poéticamente como el hombre habita esta tierra". ¿Qué significa entonces el verso?

¿Para qué poetas en tiempos de miseria?

No creo que haya otro momento mejor que éste para volver a esta pregunta. Ahora exactamente cuando todo parece ya perdido para siempre. ¿O fue asỉ desde el comienzo y lo hemos olvidado? Cuando el más puro y hondo de los poetas románticos renegó de su especie y abandonó a su tribu, a nadie pareció importarle. El mejor que nadie sabía que el poeta 
siempre ha estado de más entre nosotros. Que es un intruso, un rezagado - espíritu viejo, voz antigua - y que su lenguaje - el ritmo de sus versos - siempre ha palpitado a un ritmo diferente al de los hombres. Pero ¿quién si no él nos ha enseñado cómo vivir en esta tierra inhóspita y ajena? ¿No fue él acaso quien con las cenizas del fuego primitivo levantó la casa en que vivimos: el lenguaje"? ¿El quien nos dio la Ley que nosotros hemos olvidado? La misma Ley que está casi perdida en las turbias aguas de las religiones de nuestro tiempo. ¿Perdida o confundida o fusionada? Si el poeta nos enseñó a oír las voces que nacen de las cosas, lo hemos olvidado.

En un tiempo en que estamos más lejos que nunca de nuestros muertos lo mejor será guardar silencio y permanecer en actitud de quien espera, por si el espíritu decide volver. 